COSPAR-02 B0.3-F3.3-0032-02

$34^{\text {th }}$ COSPAR Scientific Assembly,

The World Space Congress 2002

10-19 Oct 2002/Houston, Texas

\title{
NON-ROCKET EARTH-MOON TRANSPORT SYSTEM
}

\section{Alexander Bolonkin* \\ Former NASA Senior Research Associate}

T/Fax 850-862-6113, 718-339-4563; E-mail: Bolonkin@aol.com; http://Bolonkin.narod.ru

$\boldsymbol{R}$ - radius [m];

$\underline{\text { Abstract }}$

This paper proposes a new method and transportation system to travel to the Moon. This transportation system uses a mechanical energy transfer and requires only minimal energy so that it provides a "Free Trip" into space. The method uses the rotary and kinetic energy of the Moon.

This paper presents the theory and results of computations for the project provided Free Trips (without rockets and spend a big energy) to the Moon for six thousand people annually.

The project uses artificial materials like nanotubes and whiskers that have a ratio of tensile strength to density equal 4 million meters. In the future, nanotubes will be produced that can reach a specific stress up 100 millions meter and will significantly improve the parameters of suggested project.

The author is prepared to discuss the problems with serious organizations that want to research and develop these innovations.

Nomenclature (metric system):

$a$ - relative cross-section area of cable;

$a_{m}$ - relative cross-section area of Moon cable;

$A$ - cross-section area of cable $\left[\mathrm{m}^{2}\right]$;

$A_{o}$ - initial (near planet) cross-section area of cable $\left[\mathrm{m}^{2}\right]$;

$D$ - distance from Earth to Moon [m], $D_{m i n}=356,400 \mathrm{~km}$,

$D_{\max }=406,700 \mathrm{~km}$;

$D$ - specific density of the cable $\left\{\mathrm{kg} / \mathrm{m}^{3}\right]$;

$\boldsymbol{E}$ - delivery energy of $1 \mathrm{~kg}$ load mass $[\mathrm{j}]$;

g - gravity;

$\boldsymbol{g}_{o}$ - gravitation at the $\boldsymbol{R}_{0}\left[\mathrm{~m} / \mathrm{s}^{2}\right]$; for Earth $\boldsymbol{g}_{o}=9.81 \mathrm{~m} / \mathrm{s}^{2}$;

$g_{m}$ - gravitation on Moon surface $\left[\mathrm{m} / \mathrm{s}^{2}\right]$;

$H$-altitude [m];

$\boldsymbol{H}$ - cable tensile stress $\left[\mathrm{n} / \mathrm{m}^{2}\right]$;

$\boldsymbol{H}_{p}$ - perigee altitude [m];

$k=\sigma \gamma-$ ratio of cable tensile stress to density [nm/ $/ \mathrm{kg}$;;

$K=k / 10^{\wedge} 7-$ coefficient [million meters];

Copyright @ 2002 by the International Astronautical

Federation or the International Academy of Astronautics. All rights reserved.

*Senior researcher of the USA National Research Council in Eglin AFB.
$\boldsymbol{R}_{o}$ - radius of planet [m];

$\boldsymbol{R}_{m}$ - radius of Moon [m];

$V$ - volume of a cable $\left[\mathrm{m}^{3}\right]$;

$V_{d}$ - delivery speed $[\mathrm{km} / \mathrm{sec}]$;

$V_{r}$ - maximum admitted cable speed $[\mathrm{m} / \mathrm{sec}]$;

$W$ - mass of a cable $[\mathrm{kg}]$;

$\sigma \cdot($ or $H)$ tensile strength $\left[\mathrm{n} / \mathrm{m}^{2}\right]$;

$\omega$ - angle speed of a planet $[\mathrm{rad} / \mathrm{sec}]$;

$\omega_{m}$ - angle speed of the Moon [rad/sec].

$\gamma$-density of cable $\left[\mathrm{kg} / \mathrm{m}^{3}\right]$.

\section{Introduction}

At present, rockets are used to deliver payloads into space and to change the trajectory of space ships and probes. This method is very expensive in the requirement of fuel, which limits the feasibility of space stations, interplanetary space ships, and probes. Since 1997 the author has proposed a new revolutionary transport system for (1) delivering payloads and people into space, (2) accelerating a space ship for interplanetary flight, and (3) changing the trajectory of space probes. This method uses a mechanical energy transfer, energy of moved down loads, and the kinetic energy of planets, of natural planet satellites, of asteroids, and other space bodies. The author has not found an analog for this space mechanical energy transfer or similar facilities for transporting a payload to space in literature and patents.

The present method does not require geosynchronous orbit (which is absent from most planets, moons, and asteroids which have a weak gravitation) and instead, uses the kinetic and rotational energy of the space body to modify the trajectory and impart additional speed to the artificial space apparatus. The installation has a cable transport system and used the Moon as a counterbalance. The suggested Transport System uses a loads moved in opposed direction for balancing and decreasing a spend energy. The cable may be also used for launching or modifying the speed or direction the space vehicle.

Brief history. There are many articles that develop a tether method for a trajectory change of space vehicles [1]-[2] and there is an older idea of a space elevator (see reviews in [4]). In the tether method two artificial bodies 
are connected by cable. The main problem with this method is that it requires energy for increasing the rotation of the tether system (motorized tether [2]). The problem is how to rotate it with a flexible cable and what to do with momentum after launch if the tether system is used again, etc. If this system is used only one time, it is worse then conventional rocket because it losses the second body and requires a large source of energy.

In the suggested method a balance, space vehicle is connected to a natural body (planet, asteroid, moon). The ship gets energy from the natural body and does not have to deal with the natural body in the future.

In the older idea, a space elevator is connected between a geosynchronous space station and the Earth by cable [4]. This cable is used to deliver a payload to the station. The main problems are the very large cable weight and a delivery of the energy for movement of the load container.

The other author non-rocket methods are presented in [3],[10]-[17].

In this suggested transport system the drive station (load engine) is located on the Earth (South) Pole, or Earth aircraft, or the Moon and transfers energy to the load container and to middle Space Stations with a very simple method (see Projects in [15]). The author also found and solved the differential equations of the cable for an equal stress for a complex Earth-Moon gravitation field which allows a decrease the cable weight by several times.

The main difference of the offered method is the use of the planet kinetic and rotational energy for free trip to the Moon and another planet, for example, Mars (see the project \#2 in [16], capability is 2000 men of annually).

In the proposed project with a capability is 6,000 tourists in year, the author suggests a method to connect Moon and Earth by a load cable. He solves the problem to transfer the energy to load container, finds the cable of equal stress, and shows a possibility of this project in the near future.

\section{Brief Description, Theory, and Computation of Innovations}

The objective of these innovations is to: a) provide an inexpensive means to travel to outer space and other planets, b) simplify space transportation technology, and c) eliminate complex hardware. This goal is achieved by new space energy transfer for long distance, by using either engines located on a planet (e.g., the Earth or Moon), the kinetic and rotational energy of a planet (e.g. the Moon, the Earth, the Mars, etc.), or the kinetic and rotational energy of the natural space bodies (e.g. asteroids, meteorites, comets, planet moons, etc.) $[13],[15]$. Below is the theory and research for four projects, which can be completed in the near future.
Description. A proposed centrifugal Moon cable transport system is shown in Fig.1. The system includes

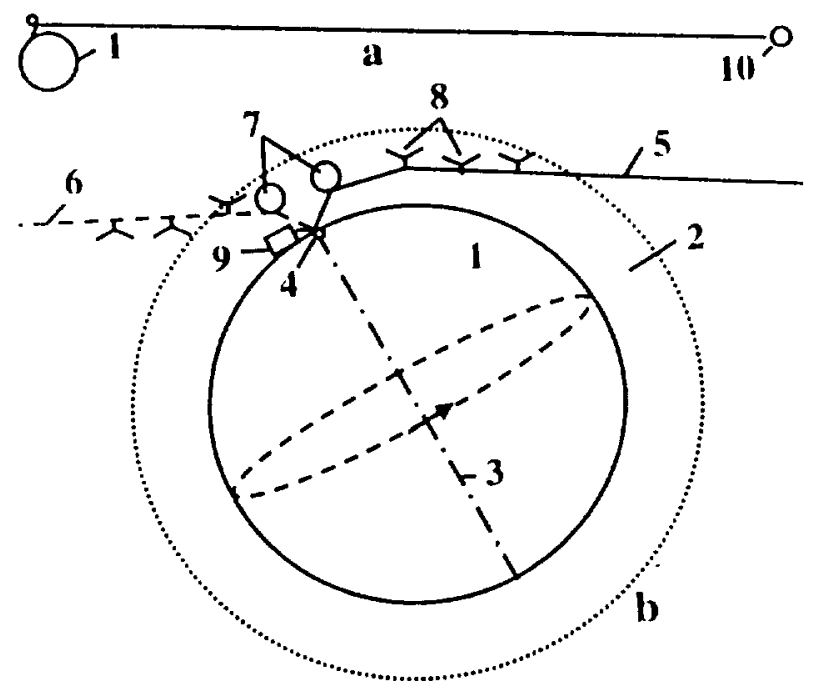

Fig.1. The offered Earth-Moon Transport System. One end is connected to Earth Pole. The second end is connected to the Moon. Notation: 1 - the Earth; 2 - Earth atmosphere; 3 - axis of Earth rotation; 4 - Earth Pole; 5 Earth-Moon cable transport system in right position; 6 Earth-Moon system in left position; 7 - air balloon; 8 support wing; 9 - drive station; 10 - Moon.

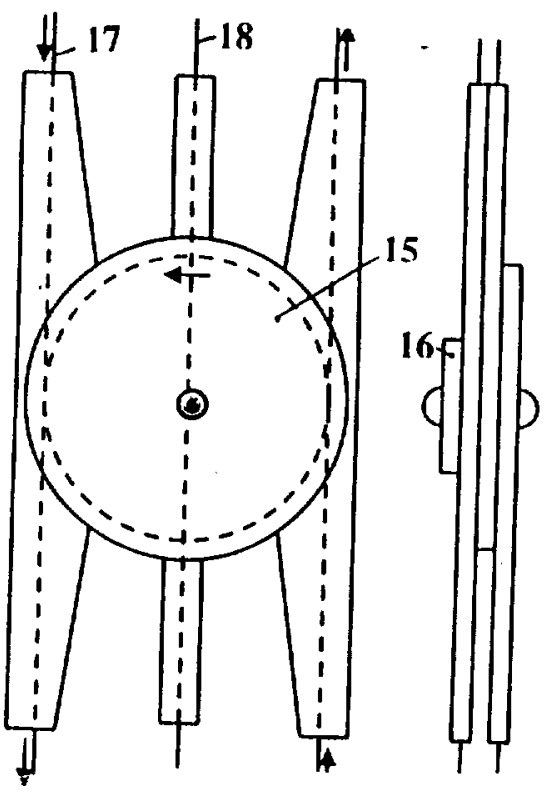

Fig.2. Roller connected the two chains of Transport System. Notation: 15 - roller, 16 - brake, 17 - transport cable, 18 - main cable.

a drive station located on Earth South Pole, and the cable transport system having three cables: a main 
(central) cable of equal stress, and two transport cables, which include a set of mobile cable chains connected sequentially one to other by the rollers (fig.2). One end of this set is connected to the Moon, the other end is connected to the Earth Pole. Such a separation is necessary to decrease the weight of the transport cables, since the stress is variable along the cable. This transport system design requires a minimum weight because at every local distance only the required amount of cable is needed of the diameter for the local force. The load containers are also connected to the chain. When containers come up to the rollers, they move past the rollers and continue their motion up the cable. The entire transport system is driven by the any conventional motor located in the Earth drive station, space station, and (or) on the Moon. When payloads are not being delivered into the space, the system may be used to transfer mechanical energy to the Moon (load cabin, the space station). This mechanical energy may also be converted to any other sort energy.

Most space payloads, like tourists, must be returned to Earth. When one container is moved up, then another container is moved down. The work of lifting equals to the work of descent, except small loss in the upper and lower rollers. The suggested transport system lets us fly into space without spending enormous energy. This is reason why the method and system are named a "Free Trip".

Near the Pole the cable is supported in atmosphere by air balloons (about Pole) and wing devices. The rotate cable has speed zero at the Pole and about $190 \mathrm{~m} / \mathrm{sec}$ at maximum distance $2700 \mathrm{~km}$ in right position of fig.l. When the cable is located in left position, part wings may be out of atmosphere and not work.

Devices shown on fig. 3 are used to change the cable length (or chain length). If the cable material has a very high ratio of an admissible stress/density the chain may be one. The transport system then has only one main cable. This design has many problems, for example, in the transfer of large amounts of energy to the load cabin.

When offered transport system is not used for transportation, that may be used for a production of energy from Moon movement. Every 29 days the Moon removes from Earth. The Moon pull the cable and produce a mechanical energy. If cable can keep 9 tons, the power can reach 2.3 millions watts.

The other design of suggested Earth-Moon Transport system is presented on fig.4. In this variant the end of cable is connected to aircraft 29 located in Earth atmosphere.

This Installation may be used for an inexpensive trip from the Earth to the Moon and back. The upper end of the System is connected to the Moon. The lower end of the System is connected to an aircraft (or buoy), which flies (i.e. glides or slides) at atmosphere along the planet's surface with speed $440 \mathrm{~m} / \mathrm{sec}$. The aircraft (or Moon) has a device, which allows the length of cable to
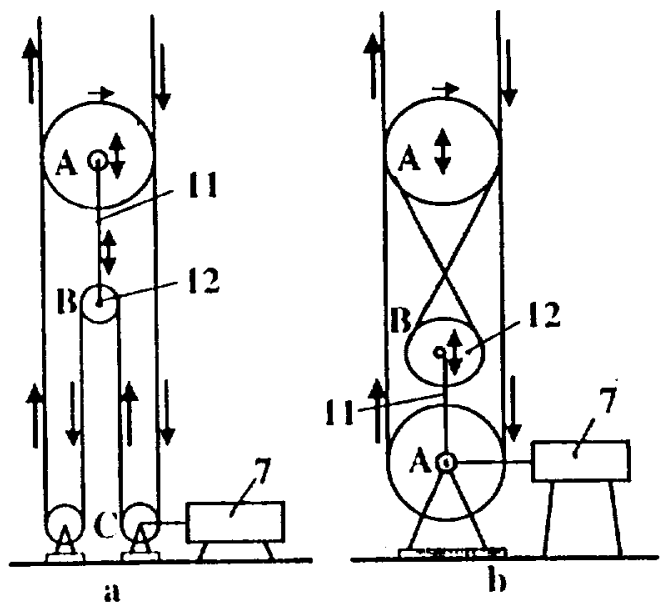

Fig.3a,b. Two mechanisms for changing the rope length in the Transport System (They are same for the space station). Notations: 11 - the rope which is connected axis $A, B$. This rope can change its length (the distance $\boldsymbol{A B}) ; 12$ - additional rollers.

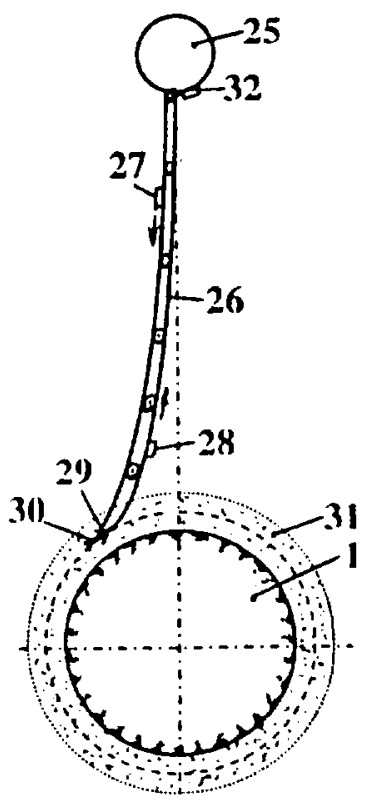

Fig.4. The Transport System for Earth-Moon connected to aircraft. Notations: 1 - Earth, 25-Moon, 26 suggested Moon Transport System, 27,28 - load cabins, 29 - aircraft, 30 - cable control, 32 - engine.

be changed. The device would consist of a spool, motor, brake, transmission, and controller. The facility could have devices for delivering people and payloads 
to the Moon and back. The delivery devices include: containers, cables, motors, brakes, and controllers. If the aircraft is small and the cable is strong then the motion of the Moon can be used to move the airplane. For example (see enclosed project), if the airplane weighs 15 tons and has an aerodynamic ratio (the lift force to the drag force) equal 5 , a thrust of $3000 \mathrm{~kg}$ would be enough for the aircraft to fly for infinity without requiring any fuel. The aircraft could use a small engine for maneuverability and temporary landing. If the planet has an atmosphere (as the Earth) the engine could be a turbine engine. If the planet does not have an atmosphere, a rocket engine may be used.

If the suggested Transport System is used only for free thrust ( 9 tons), the system can thrusts the three named supersonic aircraft or produces up to 40 millions watt energy. It more the in Pole variant because Earth equator speed in 20 times more then eccentricity speed of Moon.

A different facility could use a transitional space station located at the zero gravity point between the planet and the planet's moon. Figures 5 shows a sketch of the temporary landing of airplane on the planet surface. The aircraft increases the length of the cable, flies ahead of the cable, and lands on a planet surface. While the planet makes an angle turn $\left(\alpha+\beta=30^{\circ}\right.$ degrees) the aircraft can be on a planet surface. This time equals about 2 hours for the Earth, which would be long enough to load payload on the aircraft.

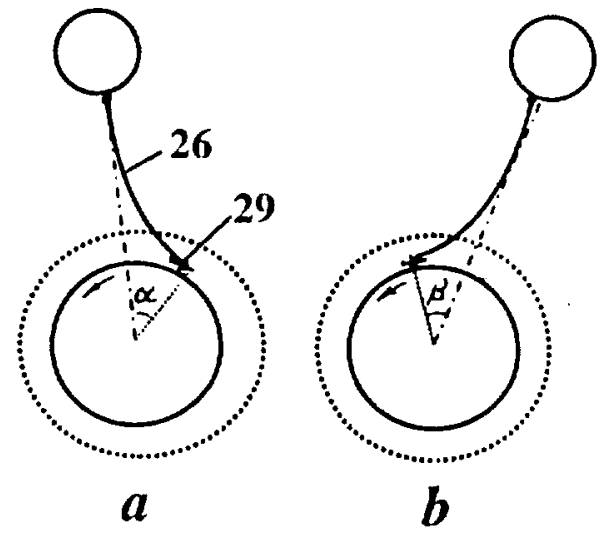

Fig.5. Landing of the Moon aircraft on the Earth surface.

The Moon's orbit has an eccentricity. If the main cable is strong enough, the Moon may used to pull a payload (space ship, man cabin), by trajectory to an altitude of about 60,000 kilometers every 27 days (fig.5). For this case, the length of the main cable from the Moon to the container does not change and when the Moon increases its distance from the Moon to the Earth, the Moon lifts the space ship. The payload could land back on the planet at any time if it is allowed to slide along the cable. The Moon's energy can be used also for an inexpensive trip around of the Earth (Figs.1) by having the moon "drag" an aircraft around the planet (using the Moon as free thrust engine). The Moon tows the aircraft by the cable at supersonic speed, about $440 \mathrm{~m} / \mathrm{s}$ (Max Number is 1.5 ).

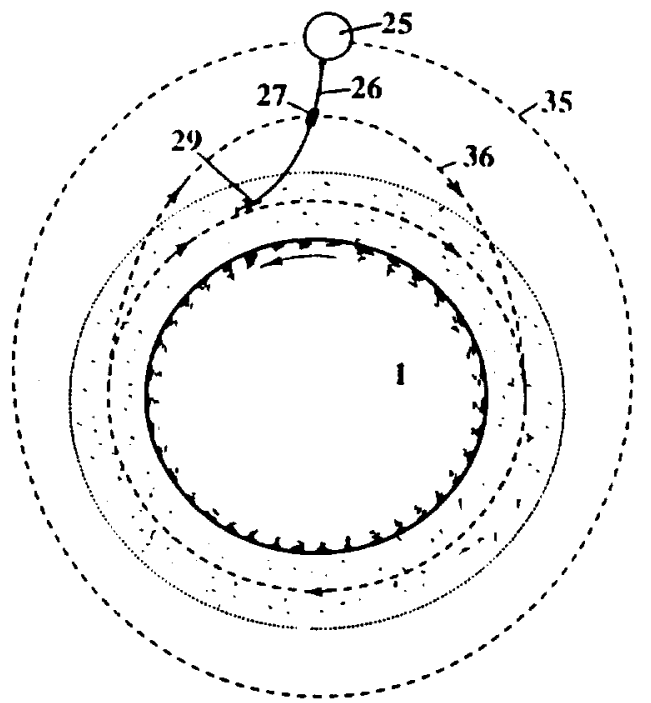

Fig.6. Employment of the Moon for delivering of space ship at altitude 60 thousand $\mathrm{km}$. Notation: 27 - space ship, 35 - trajectory of Moon, 36 - elliptic trajectory of space ship.

\section{Theory of Equal Stress Cable from Earth to Moon}

1. The equation of the equal stress cable from the Earth to the may be written and solved same way as the equation (1). The result is below

$$
a_{m}(R)=A / A_{o}=\exp \left[g_{o} B(R) / k\right] ;
$$

where

$$
\begin{aligned}
& B(R)=R_{o}-R_{o}{ }^{2} / R_{-} g_{m} R_{m}{ }^{2}\left[1 /(D-R)-1 /\left(D-R_{o}\right)\right] / g_{o}- \\
& -\omega_{m}{ }^{2}\left(R^{2}-R_{o}{ }^{2}\right) / 2 g_{a} .
\end{aligned}
$$

2. The mass of cable is

$$
W=(F, k) \int_{R_{o}}^{R} a_{m} d R .
$$

3. The volum of cable is

$$
V=\left(F_{o} / \sigma\right)_{R_{0}}^{R} a_{m} d R .
$$

The figs.7-9 represent the computation for maximum distance from Earth to Moon.

\section{Cable discussing.}

Today's industry widely produces artificial fibers, which have tensile strength of 3-5 times more than steel and a density of 4-5 times less then steel. There are experimental fibers (whiskers) which have tensile strength 30-100 times more than a steel and density 2 to 


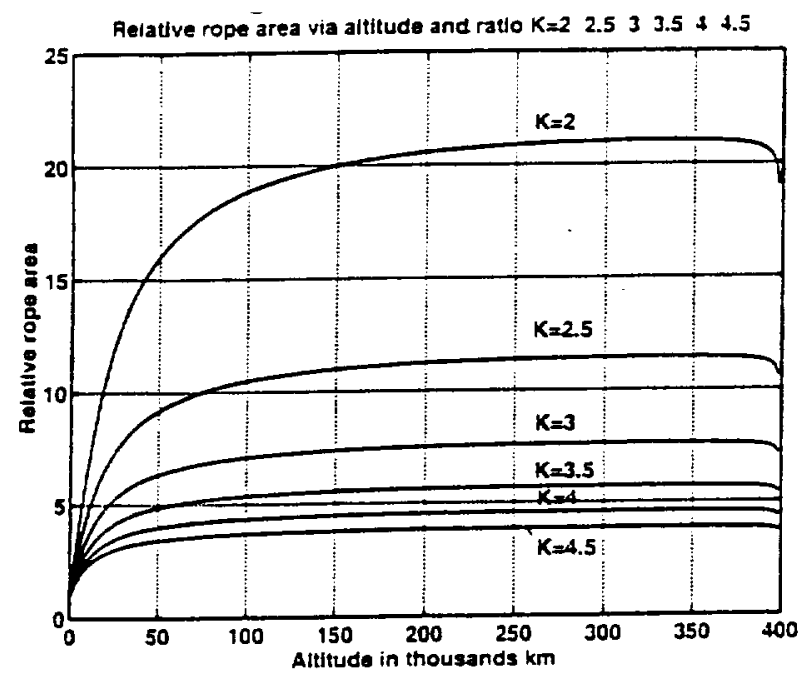

Fig.7. Relative cable area via a maximum altitude to the Moon (up 400,000km) and the coefficient $K=2-4.5$.

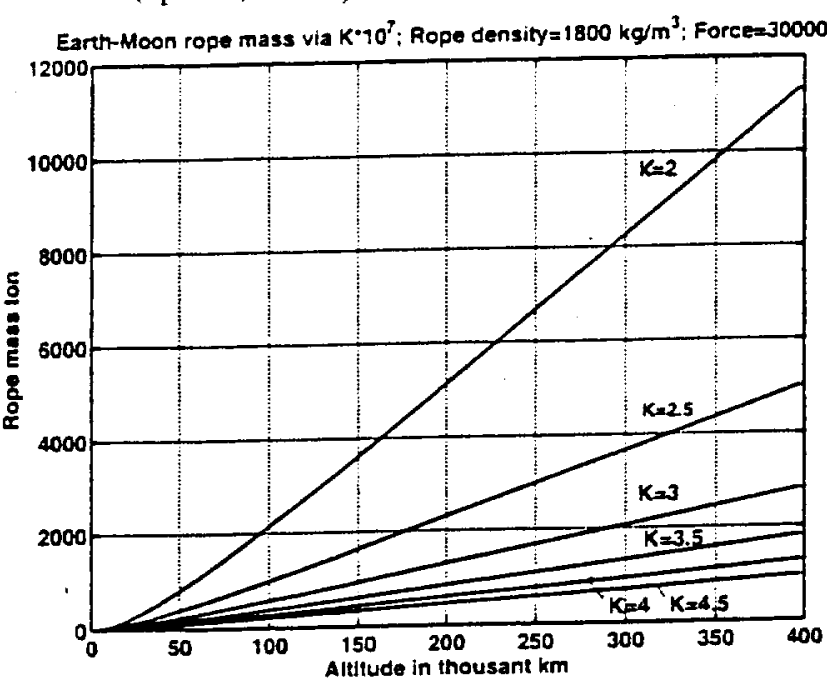

Fig.8. The Earth-Moon cable mass via altitude (in thousands $\mathrm{km}$ ) for cable density $1800 \mathrm{~kg} / \mathrm{m} 3$, delivery mass 3 tons, and the coefficient $K=2-4.5$.

5 times less than steel. For example, in the book [3] "Advanced Fibers and Composites", by F. S. Galasso, 1989 , p.158, there is a whisker $C_{D}$, which has the tensile strength $H=8000 \mathrm{~kg} / \mathrm{mm}^{2}$ and density (specific gravity) $D=3.5 \mathrm{~g} / \mathrm{cm}^{3}$. If we take an admitted strength of 7000 $\mathrm{kg} / \mathrm{mm}^{2}\left(H=7 \times 10^{10} \mathrm{n} / \mathrm{m}^{2}, D=3500 \mathrm{~kg} / \mathrm{m}^{3}\right)$ then the ratio, $D / H=0.05 \times 10^{-6}$ or $k=H / D=20 \times 10^{6}, K=\mathrm{k} / 10^{7}=2$. Although the graphite fibers are strong $\left(H / D=10 \times 10^{6}\right)$, they are at best still ten times weaker than theory predicts.

The mechanical behavior of nanotubes [5] also has provided excitement because nanotubes are seen as the ultimate carbon fiber, which can be used as reinforcement in advanced composite technology. Early theoretical work and recent experiments on individual nanotubes (mostly MWNT's) have conformed that nanotubes are one of the stiffest material ever made. Whereas carbon-carbon covalent bonds are one of the strongest in nature.

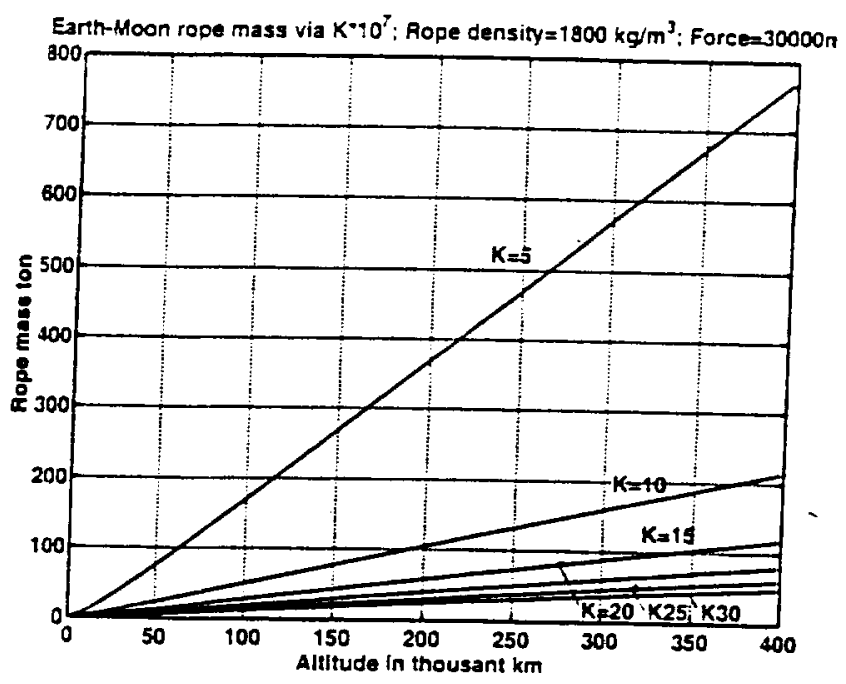

Fig.9. The Earth-Moon cable mass via altitude (in thousands $\mathrm{km}$ ) for cable density $1800 \mathrm{~kg} / \mathrm{m} 3$, delivery mass 3 tons, and the coefficient $K=5-30$.

For example, whiskers from Carbon nanotubes (CNT) have a tensile strength of 200 Giga-Pascals and Young's modulus over 1 Tera Pascals (1999). The theory predicts 1 Tera Pascals and Young modules 1-5 Tera Pascals. The hollow structure of nanotubes makes them very light (a specific density varies from $0.8 \mathrm{~g} / \mathrm{cc}$ for SWNT's up to $1.8 \mathrm{~g} / \mathrm{cc}$ for MWNT's, compared to 2.26 $\mathrm{g} / \mathrm{cc}$ for graphite or $7.8 \mathrm{~g} / \mathrm{cc}$ for steel).

Specific strength (strength/density) $K=k / 10^{7}$ (in million meters) is important in the design of our transportation systems and space elevator; nanotubes have this value at least 2 orders of magnitude greater than steel. Traditional carbon fibers have specific strength 40 times that of steel. Whereas nanotubes are made of graphite carbon, they have good resistance to chemical attack and have high terminal stability. Oxidation studies have shown that the onset of oxidation shifts by about $100^{\circ} \mathrm{C}$ to higher temperatures in nanotubes compared to high modulus graphite fibers. In vacuum or reducing atmospheres, nanotubes structures will be stable to any practical service temperature. Some American firms promise to produce the nanotubes in 2-3 years. Newsletter Chim.\&Eng. of $9 / 8 / 01$ informed that $300 \mathrm{~kg}$ of nanotubes will be produced in the USA in 2002.

The price of the whiskers $\mathrm{SiC}$ produced Carborundun Co. with $\sigma=20,690 \mathrm{MPa}, \gamma=3.22 \mathrm{~g} / \mathrm{cc}$ were $440 \$ / \mathrm{kg}$ in 1989.

Below the author provides a brief overview of the annually research information regarding the proposed experimental (tested) fibers. In addition, the author has also solved additional problems, which appear in these projects and which can look as difficult as the proposed ground or space transportation technology. The author is prepared to discuss the problems with serious organizations, which want to research and develop their projects. 
Cable performance. Let us to consider the following experimental and industrial fibers. whiskers, and nanotubes:

1. Experimental nanotubes CNT (Carbon nanotubes) have tensile strength 200 Giga-Pascals (20000 $\left.\mathrm{kg} . / \mathrm{mm}^{2}\right)$, Young's modules is over 1 Tera-Pascal, specific density $\gamma=1800 \mathrm{~kg} / \mathrm{m}^{3}(1.8 \mathrm{~g} / \mathrm{cc})(2000$ year). For safety factor $n=2.4, \quad \sigma=8300$ $\mathrm{kg} / \mathrm{mm}^{2}=8.3 \times 10^{10} \quad \mathrm{n} / \mathrm{m}^{2}, \quad \gamma=1800 \mathrm{~kg} / \mathrm{m}^{3}, \quad(\sigma / \gamma$ ) $=46 \times 10^{6}, K=4.6$. The nanotubes SWNT"s have density $0.8 \mathrm{~g} / \mathrm{cc}$, the nanotubes MWNT's have the density $1.8 \mathrm{~g} / \mathrm{cc}$. About $300 \mathrm{~kg}$ nanotubes will be produced at the USA in 2002.

2. Whiskers $C_{D}$ has $\sigma=8000 \mathrm{~kg} / \mathrm{mm}^{2}, \gamma=3500 \mathrm{~kg} / \mathrm{m}^{3}$ (1989) [3,p.158].

3. Industrial fibers have $\sigma=500-620 \mathrm{~kg} / \mathrm{mm}^{2}, \gamma=1800$ $\mathrm{kg} / \mathrm{m}^{3}, \sigma / \gamma=2,78 \times 10^{6}$.

Issues [3]-[5].

\section{Technical Parameters of Project.}

The following is some data for estimating the main transport system parameters for connecting to the Moon to provide inexpensive payload transfer between the Earth and the Moon. The system has three cables. Every cable can keep the force 3 tons. Material of cable has $K=4$. All cables would have cross-sectional areas of an equal stress. The cable has a minimal cross-sectional area $A_{0}$ of $0.42 \mathrm{~mm}^{2}$ (diameter $d=0.73 \mathrm{~mm}$ ) and maximum cross-sectional area $A_{m}$ of $1.9 \mathrm{~mm}^{2}(d=1.56$ $\mathrm{mm})$. The mass of the main cable would be 1300 tons (Fig.8). The total mass of the main cable plus the two container cables (for delivering a mass $3000 \mathrm{~kg}$ ) equals 3900 tons for the delivery Transport system Fig.l. If we have cable from nanotubes with $K=10$, the total weight will be 640 tons, and if the cable has $K=15$, the request total cable weight will be 340 tons (see fig.9). An inexpensive means of the payload delivery between the Earth and the Moon could be developed. An elapsed time for the Moon trip at a speed of $6 \mathrm{~km} / \mathrm{sec}$ would be about 18.5 hours. The annual delivery capably is 1320 tons in both directions or about 6,000 tourists.

\section{Conclusion}

The new materials makes the suggested transport system and projects realistic for a free trip to outer space without spending of energy in future. The author is prepared to discuses the project details with serious organizations that have similar research and development goals.

\section{Acknowledge}

The author wishes to acknowledge scientist $\mathrm{Dr}$. H. Pfister from Air Force Research Laboratory AFRL MNG (Eglin AFB, Florida, USA) his help in editing and correcting my English.

\section{References:}

1. Edited by M.L. Cosmo and E.C. Lorenzini. Tethers in space handbook. $3^{\text {rd }}$ Edition. Smithsonian Astronomic Observatory. December, 1997.

2. D.V. Smitherman Jr., Space Elevators, NASA/CP2000-210429.

3. F.S. Galasso, Advanced Fibers and Composite, Gordon and Branch Science Publisher, 1989.

4. Carbon and High Perform. Fibers, Directory, 1995.

5. M.S. Dresselhous, Carbon Nanotubes, Springer, 2000.

6. A.A. Bolonkin, "Hypersonic Gas-Rocket Launch System.", AIAA-2002-3927. $38^{\text {th }}$ AIAA/ASME/ SAE/ASEE Joint Propulsion Conference and Exhibit, 7-10 July, 2002. Indianapolis, IN, USA.

7. A.A.Bolonkin, Transport System for Delivery Tourist at Altitude $140 \mathrm{~km}$ and back. IAC-02IAA.1.3.03. $53^{\text {rd }}$ International Astronautical Congress. The World Space Congress - 2002, 1019 Oct 2002/Houston, Texas.

8. A.A.Bolonkin, Non-Rocket Missile Rope Launcher, IAC-02-IAA.S.P.14. 53 ${ }^{\text {rd }}$ International Astronautical Congress. The World Space Congress $-2002,10-19$ Oct 2002/Houston, Texas.

9. A.A.Bolonkin, Hypersonic Launch System of Capability up 500 tons per day and Delivery Cost $\$ 1$ per Lb. IAC-02-S.P.15. 53 ${ }^{\text {rd }}$ International Astronautical Congress. The World Space Congress $-2002,10-19$ Oct 2002/Houston, Texas.

10. A.A.Bolonkin, Employment Asteroids for Movement of Space Ship and Probes. IAC-02S.6.04. $53^{\text {rd }}$ International Astronautical Congress. The World Space Congress - 2002, 10-19 Oct 2002/Houston, Texas.

11. A.A.Bolonkin, Non-Rocket Space Rope Launcher for People, IAC-02-V.P.06. 53 $3^{\text {rd }}$ International Astronautical Congress. The World Space Congress -2002, 10-19 Oct 2002/Houston, Texas.

12. A.A.Bolonkin, Inexpensive Cable Space Launcher of High Capability. IAC-02-V.P.07. $53^{\text {rd }}$ International Astronautical Congress. The World Space Congress - 2002, 10-19 Oct 2002/Houston, Texas.

13. A.A.Bolonkin, Optimal Inflatable Space Towers of High Height. COSPAR 02-A-02228. $53^{\text {rd }}$ International Astronautical Congress. The World Space Congress - 2002, 10-19 Oct 2002/Houston, Texas.

14. A.A.Bolonkin, Non-Rocket Earth-Mars Transport System. COSPAR 02-A-02226. $53^{\text {rd }}$ International Astronautical Congress. The World Space Congress -2002, 10-19 Oct 2002/Houston. Texas. 